\title{
Exploring Teachers' Perception on Successes and Challenges Associated with Digital Teaching Practice During COVID-19 Pandemic School Closures
}

\author{
Sadaf Taimur ${ }^{1 *}$, Hassan Sattar ${ }^{2,3}$, Erin Dowd ${ }^{4}$ \\ ${ }^{1}$ Graduate Program in Sustainability Science-Global Leadership Initiative, The University of Tokyo, Kashiwa, JAPAN \\ ${ }^{2}$ Silver Oaks International Education Services Group, UAE \\ ${ }^{3}$ Silver Oaks International Education Services Group, PAKISTAN \\ ${ }^{4}$ JRNEY Consulting, New Hampshire, USA \\ *Corresponding Author: sadaf.taimur@s.k.u-tokyo.ac.jp
}

Citation: Taimur, S., Sattar, H., \& Dowd, E. (2021). Exploring Teachers' Perception on Successes and Challenges Associated with Digital Teaching Practice During COVID-19 Pandemic School Closures. Pedagogical Research, 6(4), em0105. https://doi.org/10.29333/pr/11253

\begin{abstract}
ARTICLE INFO
Received: 22 Dec. 2020

Accepted: 8 Sep. 2021

ABSTRACT

The current phenomenological study was undertaken, during the COVID-19 pandemic induced school closures, with the purpose to explore successes and challenges of implementing virtual education and collecting suggestions for improving virtual teaching practice. Data was collected using purposive sampling via social media, using open-ended survey. 141 teachers, teaching kindergarten and elementary school, from different regions submitted their responses. In our research findings, three success themes and five major challenges have emerged from the voice of teachers experiencing a rapid and unprepared shift to virtual education. Suggestions for improving digital education revolved around engagement strategies, training, access, school policies and collaboration among teachers. The finding of the research can help in informing areas of focus for reimagining the approach to education for an uncertain future.
\end{abstract}

Keywords: COVID-19, challenges, digital teaching practice, education, elementary school, preschool, pedagogies, virtual education

\section{INTRODUCTION}

The coronavirus disease 2019 (COVID-19) outbreak, caused by severe acute respiratory syndrome coronavirus 2 (SARS-CoV-2), was declared to be a pandemic by the World Health Organization (WHO) on $12^{\text {th }}$ March 2020 (Viner et al., 2020). The COVID-19 pandemic has affected education systems across the world, and the efforts for its containment have led to the near-closure of education institutions (schools, colleges, and universities). According to Daniel (2020) and Rogers and Sabarwal (2020), coronavirus disease is the greatest challenge national education systems have ever faced. By the middle of May 2020, approximately 190 countries closed their schools, and this closure has affected $90 \%$ of the world's student population i.e. 1.57 billion children and youth (Giannini et al., 2020; UNESCO, 2020). In a situation (of COVID-19 outbreak) where students were stopped from going to school, as face-to-face learning ceased, many governments asked educational institutions to move from traditional to virtual education and online teaching (Daniel, 2020).

\section{Virtual Education}

Virtual education (Online learning and teaching) is a form of distance education where one of its defining characteristics is the separation of the learner and the teacher (Cavanaugh et al., 2009; Keegan, 1996). Online learning primarily uses the internet to deliver instruction and content of education (Watson et al., 2004), and virtual school is an educational organization that uses webbased methods or the internet to offer K-12 courses (Clark, 2001).

Studies in literature have supported distance and virtual learning - for example, Ash and Davis (2009) proposed that during the swine flu crisis, distance learning can be supported by technologies like phone, radio, internet, TV, email communication, or phone messages. Muirhead (2000) also suggests that online education is new in schools and can be considered to embellish traditional schools and homeschooling. In another study (Anastasiades et al., 2010), Interactive Video Conferencing (IVC) system design was implemented at elementary schools in Greece, and it was determined that that IVC significantly supported collaborative synchronous learning. A study, conducted by Thamarana (2016) on distance learning via E-Learning and Virtual Learning Environment (VLE), reported these methods to be effective and innovative in achieving language learning goals. During the COVID19 pandemic, a case study on a private school using the 'Google-Meet' platform to implement online education shows that the 
quick transition to online education was successful, and the experience gained through this transition can be utilized in the future (Basilaia \& Kvavadze, 2020). As a response to the COVID-19 pandemic, around 96 countries worldwide have introduced different virtual solutions to continue the education process e.g., TV broadcasts, resources, guidelines, online libraries, online channels, video lectures (Basilaia \& Kvavadze, 2020). Although in-person schooling experience cannot be replaced fully, virtual learning education systems can engage students in productive and meaningful ways to minimize learning losses (Rogers \& Sabarwal, 2020).

\section{Teacher's Role in Virtual Settings}

Virtual education is growing in popularity in the context of elementary school education. However, while this area is attracting more researchers, it is still developing as a field of research (Lowes, 2014). Several studies (Boston, 2002; Hawkins et al., 2012; Lazarus, 2003; Murphy \& Manzanares, 2008; Murphy \& Rodriguez-Manzanares, 2009; Tallent-Runnels et al., 2006) have reported that the teachers' role, pedagogical techniques, and instructional practices, used in face-to-face learning, have to be modified for virtual settings. The selected evidence cautiously suggests that virtual education and online teaching practices can be successfully used to supplement learning if accompanied by appropriate technical environments and support.

To support the achievement of learning outcomes during face-to-face learning, a teacher implements instructional practices composed of activities, strategies, and techniques (Gauthier et al., 2004). To facilitate student learning outcomes, teachers usually combine their understanding of the content area (subject matter) with the knowledge of pedagogy (how to teach) into their instructional practice. This consideration is essential for virtual education as well, where it is important to carefully direct the integration of technology based on the teacher's knowledge of pedagogies and content (Ferdig, 2006). Therefore, online teaching requires some skills to support a teacher's role as an intersection point for technology, pedagogy, and content (Russell, 2004; Savery, 2005). To provide quality online learning opportunities to students, the primary responsibility of the teacher is to select and coordinate the technology, pedagogy, and content (Kurtz et al., 2004; Olson \& Wisher, 2002). Adopting new online teaching strategies linked to technology, pedagogy, and instructional plan may require teachers to undergo some key changes and move away from what they have experienced during offline teaching (Lee \& Hirumi, 2004; O'Neil, 2009).

\section{Teaching during COVID-19 Pandemic}

With the COVID-19 outbreak, many educational institutions had little time to prepare for the remote teaching scheme as the possible preparation could have included the staff preparation and training arrangements (Daniel, 2020). According to Rogers and Sabarwal (2020), the emergency shift to remote learning requires teachers to learn digital skills to operate technologies and to adapt the teaching-learning materials into a synchronous or asynchronous mode. The COVID-19 pandemic has allowed teachers to reinvigorate distance learning in new ways, and this experience can be used in the post-pandemic period and similar special cases.

\section{Purpose}

The current study is an attempt to explore virtual teaching practices of kindergarten and elementary school teachers (teaching age group 5 - 12, i.e., Kindergarten to Grade-6), during the COVID-19 pandemic, by investigating: (a) what successes and challenges have teachers encountered while moving to virtual teaching practice; (b) what are teachers suggesting for improving the quality of virtual teaching practice.

\section{Significance of the Study}

The purpose of the research is not to identify the universally successful pedagogies for online teaching and universal challenges and successes for implementing virtual learning but to capture practitioners' voice to highlight (a) what successes and hurdles did they encounter while implementing virtual learning; and (b) how virtual teaching practice can be improved. This kind of research is not preoccupied with identifying universal outcomes (e.g., pedagogies that have worked universally for virtual learning) but more focused on how virtual teaching experience during the pandemic induced lockdowns can inform virtual education and how it can be improved. This will help start a discussion on reimagining the curriculum children need, not only during the pandemic but also for the unimagined future shaped by the new norms of working, socializing, and learning that we still have to improve.

\section{METHODOLOGY}

The research was qualitative in nature and used phenomenological research design (Groenewald, 2004) where the aim is to describe the phenomenon while refraining from any pre-given framework and remaining true to facts. The experience of the phenomenon being captured in this research is the teaching experience in virtual setting during the COVID-19 pandemic induced lockdowns and the study was conducted from June-August 2020. The study, therefore, concentrates on what transpired, as a response, in the natural environment, without establishing any experimental design. This kind of research is concerned with capturing the phenomenon from the perspectives of people involved (Welman \& Kruger, 1999).

\section{Instrument for Data Collection}

An internet survey using Google forms as a data collection instrument was designed based on the framed research questions. It is ideal to use face to face interviews, written narratives, blogs, research diaries, online interviews, as data collection tools for phenomenology (Morrow et al., 2015). During the critical period of the COVID-19 pandemic, due to school closures, it was not possible to conduct face-to-face interviews and it was difficult to organize online interviews in different time zones: conversely, 
Table 1. Internet survey outlining the key questions

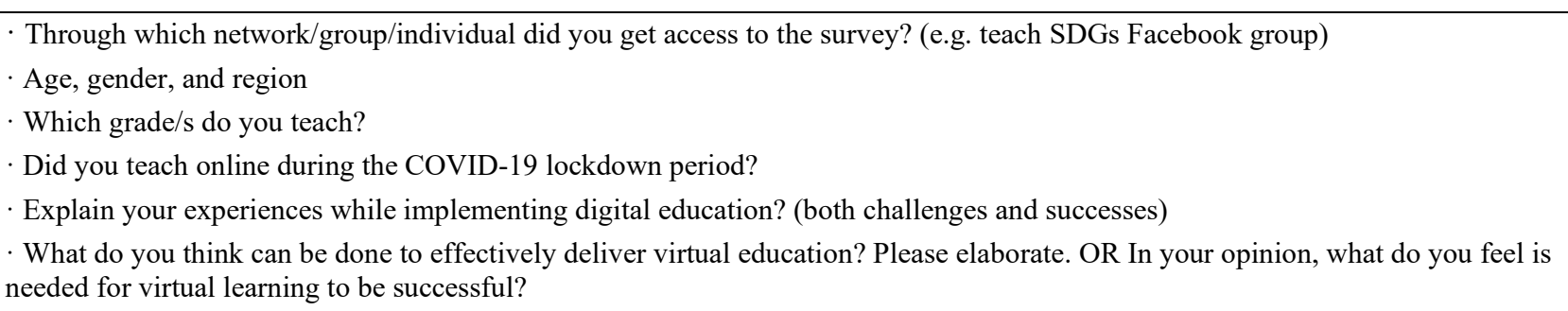

the data was collected online and therefore open-ended internet survey was used as a tool. Marshal (2006) proposed the possibility of using questionnaire with open-ended structured interview questions for phenomenology, to explore topics like first-hand experiences, perceptions, meanings, cultural differences and participant's interpretations. The internet survey method of data collection is becoming increasingly popular where the questions are administered, and responses are automatically recorded (Cornwell \& Hoagland, 2015). Most of the questions included in the internet survey were qualitative (open-ended) in nature, but demographic and informative (closed-ended) questions were also included to gather additional data about the participants. Table 1 outlines the key questions framed for data collection.

\section{Data Collection}

In the Phenomenological research, individuals are not selected because of their membership in a given population but because of their experience with the topic under investigation (which in this case is virtual teaching experience during the COVID19 pandemic lockdowns), as the study does not aim to cover the diversity but to conceptualize the common essence in the experience (Baker et al., 1992; Jansen, 2010). Therefore, data for the study was collected online using various social media platforms. Forty-seven groups and pages with teachers/educators were identified on social media networks (Facebook, Slack, Emails, Watsapp, and Linkedin), and the web-link for the internet survey (study instrument) was circulated among the participants. The administrator/s of the groups and pages were requested to promote the web-link for the internet survey. The survey was designed in a way that, after taking informed consent, only teachers teaching kindergarten and elementary school using virtual platforms during the pandemic were allowed to complete the survey. The methodology for data collection was adapted from the methodology recommendations for the recruitment of research participants on Facebook by Brickman Bhutta (2012). Brickman Bhutta (2012) mentioned that the administrators of existing Facebook groups were contacted for participant recruitment for the study stating: "all administrators received a personal message that explained the purpose of the research and asked them to send a message to the members of their groups with an invitation to join the research group" (p. 63). The current research aimed to explore the pedagogies and challenges associated with implementing virtual education during the COVID-19 pandemic; therefore, research participants' access to technology was not a challenge as teachers implementing virtual education already had access to technology.

Social media networks offer many research benefits like quickly identifying the potential respondents, creating a comprehensive sampling frame, monitoring responses, and using the referral chain to increase the individual motivation to respond to the survey (Mirabeau et al., 2013). Mirabeau et al. (2013) also identified some threats related to using social media networks for data collection: (a) self-selection bias - one social media platform can be different from others. To overcome the selfselection bias, four different social media networks were used to collect data; (b) the sampling frame might not include all the population of interest - this was not a challenge in the case of current phenomenology; (c) seeding bias - the sample might be biased towards individuals closely related to the researchers. To deal with this bias, all researchers selected the clusters/groups of teachers instead of selecting individuals, and the administrator/s of the groups were asked to encourage group members within the sampling frame to be the seeds (distribution points). Despite all these confines, social media is an effective way to get samples through chain referrals, and, despite the limitations, there is no doubt that chain referrals have significant value for exploratory studies targeting elusive populations (Faugier \& Sargeant, 1997; Penrod et al., 2003).

\section{Ethical Considerations}

The nature of the study involved human subjects. For conducting ethical research, informed consent was used. The informed consent was developed to get an agreement from the participants on their participation in the research, the purpose of the research, procedures of the research, voluntary nature of participation, measures utilized to protect confidentiality, risks and benefits of research (Groenewald, 2004). The research participants had to agree to the informed consent statement to access the data collection survey.

\section{Research Participants}

The purpose of the study directed the subjects of the study i.e. kindergarten and elementary school teachers. A purposeful sampling technique was used to collect data to achieve the research objectives. This kind of sampling is usually implemented to collect qualitative data to identify and select information-rich cases related to the phenomenon being investigated (Palinkas et al., 2015). The criteria for the purposeful sampling of the forty-seven groups and pages of teachers are as follows: (a) the social media group or page should include kindergarten and/or elementary school teachers; (b) the official language of the group or page should be English, given that survey was designed in the English language; (c) the administrator of the group or page should 


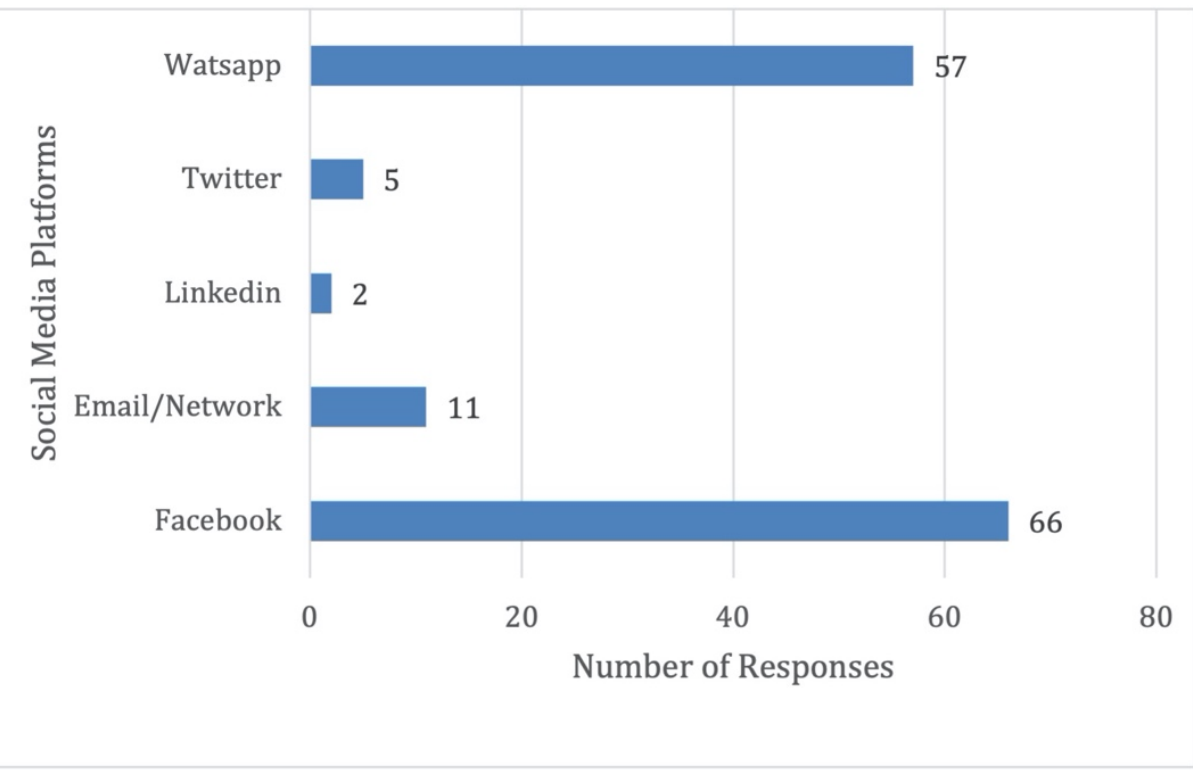

Figure 1. Number of survey responses collected via each social media platform

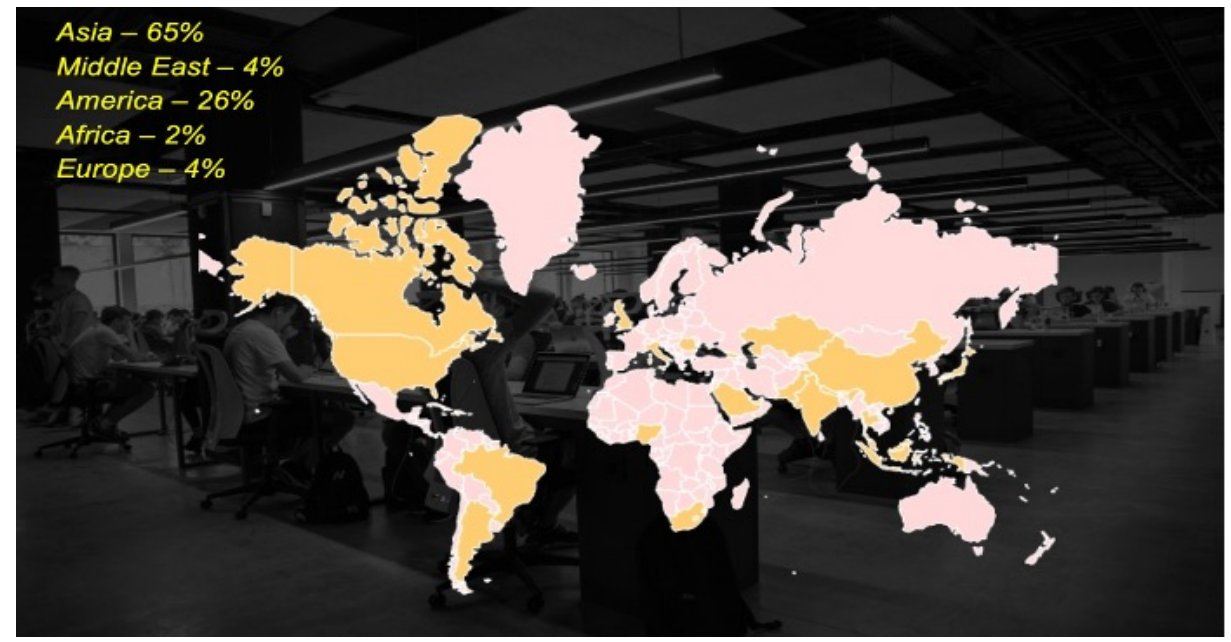

Figure 2. Map showing the regions (in yellow) from where the responses were received

agree to promote the post and to encourage teachers to act as the seed to distribute the internet survey to their network; (d) the groups/pages shall be from different parts of the world.

Our data collection method allowed us to collect qualitative responses from 141 teachers. Qualitative research samples are smaller in order to support the case-oriented analysis, fundamental to its mode of inquiry (Sandelowsk, 1996). The research employed purposive sampling, as opposed to probability sampling (employed in quantitative research), to select the informationrich cases (Patton, 1990) in the first place. The data collected revealed that most of the elementary school teachers accessed the survey through Facebook $(n=66)$ and Watsapp $(n=57)$, see Figure 1 . Only 2 teachers submitted their responses accessed the data through Linkedln.

Most of the data came from Asia ( $n=91)$ followed by America $(n=36)$ and a few responses came from the Middle East ( $n=6)$, Europe $(n=5)$, and Africa $(n=3)$. Figure 2, highlighting in yellow, represents regions from where responses to the survey were submitted.

The demographic characteristics of the participating elementary school teachers are presented in Table 2. From the table, it is evident that: (a) of the 141 respondents, the number of female teachers (129, i.e., $91.4 \%)$ far exceeds the male teachers (12, i.e., $8.5 \%)^{\prime} ;$ (b) the minimum and maximum age of the responding teachers is 23 years and 64 years respectively. 
Table 2. Demographic characteristics of the kindergarten and elementary school teachers who responded to the survey

\begin{tabular}{|c|c|c|c|c|}
\hline \multirow{2}{*}{ Region } & \multirow{2}{*}{ No. of Participants } & \multicolumn{2}{|c|}{ Gender } & \multirow{2}{*}{$\begin{array}{c}\text { Age Range } \\
\text { (min - max) (Years) }\end{array}$} \\
\hline & & $M$ & $\mathbf{F}$ & \\
\hline Asia & 91 & 9 & 82 & $23-62$ \\
\hline Middle East & 6 & 0 & 6 & $39-61$ \\
\hline America & 36 & 0 & 36 & $26-64$ \\
\hline Africa & 3 & 2 & 1 & $31-55$ \\
\hline Europe & 5 & 1 & 4 & $33-49$ \\
\hline Total & 141 & 12 & 129 & $23-64$ \\
\hline
\end{tabular}

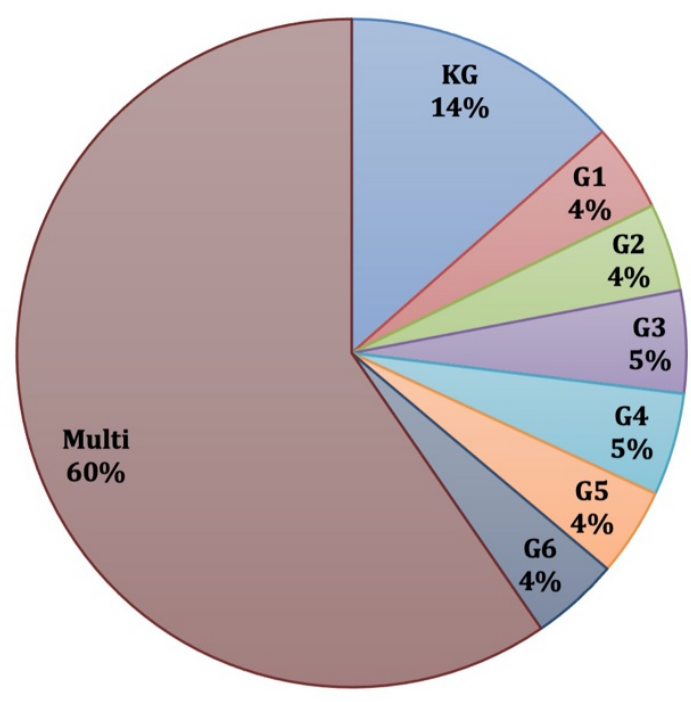

$\square$ KG $\square$ G1 $\square$ G2 $\square$ G3 $\square$ G4 $\square$ G5 $\square$ G6 $\square$ Multi

Figure 3. Percentage of teachers teaching single and multiple grades from kindergarten till grade-6

In the collected dataset, $60 \%$ of the teachers reported teaching multiple grades (between Kindergarten and Grade 6, which is consistent with practice of teachers covering multiple grades at schools) and $14 \%$ of the teachers mentioned teaching Kindergarten only (see Figure 3).

\section{DATA ANALYSIS}

The data collected from 141 participants was exported to Microsoft Excel sheets. Data with closed-ended responses (mostly demographic data) was separated from data with open-ended and detailed responses. Moustakas's (1994) method for inductive data analysis was utilized in the study. Each individual survey response was read twice to immerse in the data and then all the responses were read again, for further immersion and key concepts were recorded in the memo. Following steps were performed after initial immersion:

a. Horizontalization - Equal importance was given to each statement and then it was coded with a descriptive label.

b. Reduction and Elimination - of statements that were not relevant to the experience being investigated were eliminated by asking whether the statement carried important insight to understand the experience.

c. Clustering - Related constituents were grouped together and given thematic label. Initial clustering yielded 16 themes for successes, 28 themes for challenges and 25 themes for improvement suggestions. These steps were performed several times, separately by each author, to further reduce and group the categories. Finally, the constituents were clustered into yielded 3 themes for successes, 5 themes for challenges and 5 themes for improvement suggestions.

d. Final Identification of Themes - Survey responses were read again to verify that the themes finalized were aligned to and compatible with what research participants words. The final themes, presented within the text, culminated into an over essence of the experience.

\section{Reliability and Validity}

The reliability techniques used in the study include intercoder agreement, where independent coders evaluated a characteristic of a message and reached the same conclusion (Silverman, 2005; Tinsley \& Weiss, 2000). All three authors and an 
outside coder analyzed the data independently and then discussed codes. There was no significant difference, and the minor discrepancies were discussed and resolved to create the set of themes presented in the paper.

Validity of the study was ensured by using bracketing during data analysis for clarifying bias and mitigate the potential impacts of unacknowledged preconceptions (Tufford \& Newman, 2012). Memos as a means to examine and reflect on the researchers' engagement with data were prepared and discussed following the bracketing method recommendation by Cutcliffe (2003).

\section{RESULTS}

The results are presented as follows and summarized in Table 3.

Table 3. Summarized results with themes, key-concepts and supporting quotes

\begin{tabular}{|c|c|}
\hline Theme & Key Concept and Supporting Quotes \\
\hline \multicolumn{2}{|l|}{ Successes } \\
\hline \multirow{4}{*}{$\begin{array}{l}\text { Adaptation } \\
\text { leading to } \\
\text { learning }\end{array}$} & Key Concept \\
\hline & $\begin{array}{l}\text { For many teachers, the shift to virtual teaching was a phenomenal 'learning-by-doing' experience, not just around technology } \\
\text { platforms but also for polishing their teaching techniques. }\end{array}$ \\
\hline & Supporting Quotes \\
\hline & $\begin{array}{l}\text { "It was interesting"; "It was a great experience"; "It is successful"; "It was a good experience as I learnt to use different technologies } \\
\text { in lesson"; "This, for the first time without prior experience, was a challenging task but with time when we got familiar to it .. these } \\
\text { resources proved to be very helpful in achieving the learning objectives." }\end{array}$ \\
\hline \multirow{4}{*}{$\begin{array}{l}\text { Connection at } \\
\text { a critical time }\end{array}$} & Key Concept \\
\hline & Teachers found ‘being able to establish connection' as a positive windfall of the virtual education process. \\
\hline & Supporting Quotes \\
\hline & $\begin{array}{l}\text { "The students were so excited to video chat as a lesson and often didn't want to sign off;"....they missed and still valued the } \\
\text { connection between peers"; "Parents said that their kids look forward to the class"; "Families said students were thrilled to have } \\
\text { even a phone call and hear my voice...". }\end{array}$ \\
\hline
\end{tabular}

\begin{tabular}{ll}
\hline Virtual & Key Concept \\
Platform & Teachers viewed planning ahead and familiarizing students with the use of virtual platforms, being utilized in the lessons, to be \\
Demonstration particularly helpful when applied. \\
Supporting Quotes \\
"spent first few days just explaining how to navigate through the platform, which was worth it. I would recommend everyone to do \\
that as it worked out quite well."; "training students made it easier"; "....it saves a lot of time and makes teaching effective.".
\end{tabular}

Challenges

Students'

Engagement Many teachers highlighted that shift to virtual education has led to reducing students' engagement in the virtual classroom in various ways.

Supporting Quotes

"it was difficult to engage with students during online sessions"; "to deliver concepts and engage each and every student was a big challenge, as many students were of small age."; "Lack of motivation from some students, some of whom disappeared entirely from learning ..."

Parents' Key Concept

Engagement A vast majority of teachers found parents to be lacking in basic knowledge and skill for adjustment to the whole virtual education scheme.

Supporting Quotes

"Parents were not cooperative as they should be during online live class sessions."; "...holding parents onboard was a challenge and with the help of my line manager and coordinator I was successful."; "Families' comfort level with technology varied which led to inequality"; "it really becomes a privilege issue... students who have support in their houses were much more engaged.".

\section{Training Need Key Concept}

Teachers were extremely cognizant of being 'ill-equipped' to handle virtual education, both on the side of technology as well as pedagogy adaptation to digital platforms.

Supporting Quotes

"Most of us were ill-equipped and not trained in any form of digital education."; "Learning it was difficult as we were not familiar with it...."; "First we need to train people and create awareness for this..."; ".. we need training..."

\section{Access to Key Concept}

Digital The digital divide inequalities posed a monumental challenge owing to complete lack of or frequent disruptions in the internet

Equipment connection, both for teachers and students.

\section{Supporting Quotes}

"Sometimes difficulties occurred because of internet issues and sometimes some students didn't have upgraded devices or even devices."; "Biggest challenge was internet connection not only from my side but also from students side"; ".. there were internet and technical difficulties that were obstructive”; “...access to technology was a huge problem...”.

\section{Systematic Key Concept}

Challenges Many teachers wanting to deploy a range of activities, tools, or platforms for effective learning encountered systemic constraints (either school or by local government body).

Supporting Quotes

"We were not allowed to use platforms of our choice.."; "We were only limited to use X platform which limited our ability to really do much..... We couldn't even have videos turned on for our students until May, it was very constricting"; “..this takes away creativity.." 
Table 3 (continued). Summarized results with themes, key-concepts and supporting quotes

\begin{tabular}{|c|c|}
\hline Theme & Key Concept and Supporting Quotes \\
\hline \multicolumn{2}{|c|}{ Suggestions for Improvement } \\
\hline Students' & Key Concept \\
\hline \multirow[t]{5}{*}{ Engagement } & $\begin{array}{l}\text { Teachers gave multiple suggestions to improve students' engagement including using synchronous teaching methods and } \\
\text { using interactive, diverse and creative activities in the virtual setting. }\end{array}$ \\
\hline & Supporting Quotes \\
\hline & "My school only allowed to teach asynchronously in spring.... that didn't work, I disliked it and began synchronous lessons in late \\
\hline & May. I will prefer to begin synchronously with my students."; "I will recommend using more synchronous lessons in small groups."; \\
\hline & $\begin{array}{l}\text { "I would prefer to engage students in more hands-on experiences... it was lacking in online classes."; ".. modification in teaching } \\
\text { techniques to avoid monotony and make virtual learning a refreshing experience." }\end{array}$ \\
\hline \multirow[t]{4}{*}{ Training } & Key Concept \\
\hline & $\begin{array}{l}\text { Majority of the teachers emphasized on training teachers and students on not only digital skills but also on various digital } \\
\text { education platforms/tools. According to teacher's perspective, training parents to ensure their engagement in their children's } \\
\text { education is also crucial. }\end{array}$ \\
\hline & Supporting Quotes \\
\hline & $\begin{array}{l}\text { "For virtual education, both teachers and students as well must learn different tools and how to use them."; "..teachers need } \\
\text { training before implementation..."; "Parental awareness is required about their responsibilities while their kids are attending } \\
\text { classes. Parental support is highly required for successful virtual education." }\end{array}$ \\
\hline Access to & Key Concept \\
\hline \multirow[t]{4}{*}{$\begin{array}{l}\text { Digital } \\
\text { Equipment }\end{array}$} & $\begin{array}{l}\text { Teachers mentioned the importance of access to the internet and digital gadgets to ensure digital learning does not create a } \\
\text { learning divide }\end{array}$ \\
\hline & Supporting Quotes \\
\hline & "...facilitating students with feasible internet packages with high quality and speed. It would increase the ratio of students."; \\
\hline & $\begin{array}{l}\text { "Providing strong internet facility and ensuring the availability of gadgets with every student is crucial..."; "Every child should } \\
\text { have internet connection and digital devices..". }\end{array}$ \\
\hline \multirow[t]{4}{*}{ School's Policy } & Key Concept \\
\hline & $\begin{array}{l}\text { Teachers suggested giving more freedom to teachers for designing their lessons in the digital settings and providing the } \\
\text { appropriate teaching material to ensure effective learning. }\end{array}$ \\
\hline & Supporting Quotes \\
\hline & $\begin{array}{l}\text { "Teachers should have complete independence for conducting their lessons."; "Suggestions and improvements depend on the } \\
\text { school's policy."; "Schools need to provide teachers with the appropriate resources they need including the apps that help } \\
\text { enhance virtual education."; "... availability of more digitally interactable software to make things easy." }\end{array}$ \\
\hline \multirow[t]{4}{*}{ Collaboration } & Key Concept \\
\hline & $\begin{array}{l}\text { While implementing digital education, teachers expressed connecting and collaborating with other teachers to exchange best } \\
\text { practices. }\end{array}$ \\
\hline & Supporting Quotes \\
\hline & $\begin{array}{l}\text { "Promoting connection and collaboration vs competition will be essential for everyone involved. Allowing different members of the } \\
\text { team to do different video lessons that we can all use would maybe free us up to spend more time connecting with students and } \\
\text { learn from each other as colleagues."; "Sharing good practices is important..."; "Cooperation is important for learning..."; "... we } \\
\text { need to create communities of educators to share digital teaching methods..." }\end{array}$ \\
\hline
\end{tabular}

\section{Successes of Virtual Teaching}

Three success themes emerged from the voice of teachers experiencing a shift to virtual education without much preparation and are: (a) adaptation leading to learning; (b) connection at a critical time; (c) familiarizing students with virtual platforms. These themes are explained below:

(a) Adaptation leading to learning

For many teachers, the shift to virtual teaching was a phenomenal 'learning-by-doing' experience, not just around technology platforms but also for polishing their teaching techniques like adding snap quizzes and using multiple tools for explaining a concept. As a teacher explained: "this, for the first time without prior experience, was a challenging task but with time, when we got familiar, these resources proved to be very helpful in achieving the learning objectives."

Multiple platforms were invoked by teachers, depending on the pedagogies implemented and the learning needs of students. According to teachers, 'Tencent' had the tools to engage; 'Zoom' facilitated crafts and interactive projects; 'Kahoot' was great for motivation and engagement; 'YouTube' videos helped maximize comprehensible input at learners' own pace; while 'Google classroom' was good for organization and setting clear expectations. It indicates that not a singular platform, but a combination was necessary to replicate face-to-face teaching in an online learning environment.

A clear win, for many teachers, was the adaptation to digital education by both students and teachers. When the adjustment happened - for the trio of teachers, students and parents - the learning process was smoother. A teacher wrote, "using digital platforms was a success in a way that students were getting more comfortable with using technology for their learning purposes and were able to experience learning at a broader level." For another teacher, "seeing all the kids work in one place made marking of work easier".

(b) Connection at a critical time 
Teachers found 'being able to establish connection' as a positive windfall of the virtual education process. Most of the teachers believed that virtual education was important during the COVID-19 induced school closures. Virtual education has allowed students to connect at a very critical time when, perhaps, they were feeling a lack of connection with their school friends, teachers, and peers. As a teacher noted: "students were so excited to video chat at a lesson and often didn't want to sign off... it showed they missed and still valued the connection between peers and teachers." Another teacher mentioned: "Families said students were thrilled to have even a phone call and hear my voice..".

(c) Virtual Platform Demonstration

Teachers viewed planning ahead and familiarizing students with the use of virtual platforms, being utilized in the lessons, to be particularly helpful when applied. Many teachers highlighted that when students are familiar with the digital platforms, teachers can focus more on implementing teaching practice and less time is spent on addressing the technological challenges encountered by students during the class. One of the teachers highlighted that they "spent first few days just explaining how to navigate through the platform, which was worth it. I would recommend everyone to do that as it worked out quite well." Another teacher wrote "...it saves a lot of time and makes teaching effective."

\section{Challenges of Virtual Teaching}

Insights into the challenges encountered by teachers while moving to virtual teaching practice reflect a broad range of challenges around the following five themes: (a) student engagement; (b) parents' engagement; (c) training need; (d) access to digital equipment; (e) systematic challenges. The description of each theme is detailed below:

(a) Students' Engagement

Teachers mentioned that shift to virtual education has led to reducing students' engagement in the virtual classroom. In the virtual setting teachers were not able to interact with students, as is possible in a face-to-face classroom setting. The lack of interaction made it difficult for teachers to deliver concepts and engage each and every student. A teacher noted: ".. to deliver concepts and engage each and every student was a big challenge, as many students were of small age." Some teachers used asynchronous methods for their lessons. Asynchronous teaching methods required self-directed learning which reduced student-teacher interaction and therefore, teachers did not recommend asynchronous methods for teaching elementary school students.

On the other hand, teachers also reported that they were not able to manage discipline and control students' environment in the virtual setting and that is why many students were distracted by the home environment, noise, and availability of toys around them. In addition, some teachers reported that distractions also arose when students were not following directions and purposefully causing disruptions as a teacher mentioned: ".. struggle was classroom management ... I could not disable text-based chat for some students that were not following directions..."

In a scenario where students were not able to engage in the classroom, some teachers reported that some students "entirely disappeared from learning" owing to lack of motivation and engagement while many students were "lonely and depressed" because they were not able to engage and interact.

(b) Parents' Engagement

A vast majority of teachers found parents to be lacking in basic knowledge and skill for adjustment to the whole virtual education scheme, resulting in them being noncooperative and frustrated. Some parents managed great strategies to keep their kids engaged in virtual learning but were only able to support teachers during the online class; they could not independently use those strategies at home.

"Parents were frustrated trying to motivate students.... They had good strategies for dealing with inattention in class but could not independently use those strategies at home." (Teacher)

The level of engagement of parents was a key determinant of the benefit derived by their children through virtual learning. However, a key influencer in the 'inequality in learning' was the families' comfort level with technology varied which led to inequality. As a teacher stated: "it really becomes a privilege issue; students who have support in their houses were much more engaged".

(c) Training Need

Teachers were extremely cognizant of being 'ill-equipped' to handle virtual education, both on the side of technology as well as pedagogy adaptation to digital platforms. 'Learning by doing' is not an efficient and optimal way of getting trained in a live education environment, where many other factors, detrimental to student-learning outcomes, are simultaneously in play. Teachers were not trained to implement digital education and that hurdled effective teaching practice. Some teachers used virtual teaching practice for the first time in their whole teaching career as one of the teachers highlighted: "I have not used any of these in 36 years of teaching".

Due to the lack of training and preparation, monitoring became a humongous task for teachers and affected the feedback loop thereby nullifying an objective measurement of progress in pupil learning outcomes. As a teacher mentioned: "....photos of their work were difficult to see and therefore, feedback on their work was not always appropriate.... Still searching for the best way for students to demonstrate ability to solve algebraically so that I can correct errors."

Many teachers were not trained and experienced in virtual teaching and that is why adapting to digital education and teaching online took more time as compared to teaching a face-to-face class. An overwhelming majority of teachers found virtual teaching to be a hectic task getting in the way of work-life balance on the one hand, while requiring a number of non-educational administrative aspects on the other. As one teacher sighed: "too many passwords and websites to keep up 
with. I already have several windows open; can't present and keep an eye on managerial stuff too". A teacher found that "technology can't handle what we are asking it to do; it is tiring, frustrating and demotivating".

(d) Access to Digital Equipment

The digital divide inequalities posed a monumental challenge owing to complete lack of or frequent disruptions in the internet connection, both for teachers and students, even for well-resourced schools and homes. Most of the teachers expressed that they faced difficulties due to complete lack of internet connection or disruptions in internet connection:

"Biggest challenge was internet connection not only from my side but also from students side." ; "Even in a well-resourced school like ours with well resourced families, there were internet and technical difficulties that were obstructive." (Teachers)

In addition, access to appropriate and adequate digital devices was a major problem in relatively disadvantaged households as one of teachers highlighted: "... sometimes some students didn't have upgraded devices or even devices."

(e) Systematic Challenges

Many teachers wanting to deploy a range of activities, tools, or platforms for effective learning encountered systemic constraints (either school or by local government body). These controls put an additional limitation on the creativity and effectiveness of the virtual teaching practice. "We were only limited to use X platform which limited our ability to really do much..... We couldn't even have videos turned on for our students until May, it was very constricting." (Teacher)

\section{Suggestions for Improvement}

The themes that emerged from the data as to what suggestions teachers have for improving digital education are: (a) engagement; (b) training; (c) access to digital equipment; (d) school's policy; (e) collaboration.

(a) Students' Engagement

To ensure students' engagement in virtual classroom, based on experience, data revealed various suggestions. Teachers highlighted that synchronous teaching is more effective as compared to asynchronous teaching. Teachers regarded asynchronous teaching as time consuming and non-engaging e.g. one of the teachers used video lessons and wrote: "Making and producing videos for each lesson is very demanding and time consuming..... and they are not very effective." Most of the teachers suggested using hands-on and interactive activities for the online classes by modifying their teaching techniques creatively and by avoiding monotony using different digital platforms/tools/applications. A teacher wrote: "..using more enhanced teaching strategies and resources to make it more interactive and interesting for students."

Many teachers regarded social interactions, discourse, and relationship building as an important element of virtual education, recognizing that digital learning already creates a physical divide. Teachers suggested reducing the class size, in virtual setting, to ensure interaction for students' engagement. According to teachers' perspective reducing the teacher student ratio will not only promote student-teacher interaction but it will also promote student-student interaction.

"In order for virtual learning to be successful we need smaller class sizes .. that way teachers can make multiple groups per day and truly talk to the students and maneuver through the curriculum .. students could also talk to each other and collaborate (so important), which they can't across the huge zoom class."(Teacher)

Some teachers suggested setting up an individual virtual meeting with each student, especially in the uncertain time, to ensure interaction and their engagement in the classroom. Some teachers mentioned using social media platforms for uploading the learning materials and sharing learning content with students and their parents.

(b) Training

Majority of the teachers emphasized on training teachers and students on not only digital skills but also on various digital education platforms/tools.

".. we need to learn different software and tools that work in this regard. To make it easier for the learners to understand."(Teacher)

Many teachers mentioned that training will better equip them to modify their teaching techniques and some suggested that teachers' training should include the aspect of monitoring and feedback. ".. it will help in figuring out new ways to provide feedback and how to do that without taking more hours." This will support improvement of virtual teaching practice.

Teachers also proposed training parents on the importance of their involvement in virtual education of their children because parental support is strongly needed for successful virtual teaching and learning. Some teachers suggested training parents on digital education platforms and tools, specifically if they have younger kids. A teacher highlighted: "I would like to educate parents through virtual workshops .. to ensure best learning of their kids."

(c) Access to Digital Equipment

Data suggests that it is crucial to ensure that every child has access to digital equipment. Teachers mentioned the importance of access to the internet and digital gadgets to ensure digital learning does not create a learning divide, as one teacher wrote: "providing strong internet facilities and ensuring the availability of gadgets with every student is crucial". Although data didn't suggest how to solve this problem or who should solve this problem, but most of the teachers referred to providing students with digital equipment which can support their learning.

(d) School's Policy 
According to teachers' perspective, the design of digital teaching and learning depends on the school's policies. Practitioners suggested giving more freedom to teachers for designing their lessons in the digital settings to ensure effective learning: "Teachers should have complete independence for conducting their lessons".

To implement diversity of teaching methods in the classroom, teaching materials i.e. digital platforms and teaching resources are required to be made available to the teachers and schools should take this responsibility: "Schools need to provide teachers with the appropriate resources they need including the apps that help enhance virtual education." (Teacher)

(e) Collaboration

While implementing digital education, teachers expressed connecting and collaborating with other teachers to exchange best practices. Sharing teaching resources will also give teachers space and time to give more attention to their students and learn from each other, as a teacher noted: "promoting connection and collaboration vs. competition will be essential for everyone involved. Allowing different members of the team to do different video lessons that we can all use would maybe free us up to spend more time connecting with students and learn from each other as colleagues."

\section{DISCUSSION \& CONCLUSION}

The purpose of the current phenomenological research is to explore the successes and challenges of virtual teaching practice during the COVID-19 pandemic lockdown period and to understand teachers' suggestions for improving the quality of virtual teaching practice. Exploration with teachers revealed complex perspectives that were not consistent however, teacher found the digital teaching experience interesting. From the voices of teachers experiencing a shift to virtual education during COVID-19 pandemic lockdowns, three themes emerged for success ((a) adaptation leading to learning; (b) connection at a critical time; (c) familiarizing students with virtual platforms) and five themes surfaced for challenges ((a) student engagement; (b) parents' engagement; (c) training need; (d) access to digital equipment; (e) systematic challenges). Teachers also gave numerous suggestions for improving digital teaching practice and in this research those suggestions are categorized under the following themes: (a) engagement; (b) training; (c) access to digital equipment; (d) school's policy; (e) collaboration.

When the COVID-19 pandemic hit, most teachers were not prepared on the one hand, and on the other, the schools and governments were not ready to allocate resources for digital education at kindergarten or elementary school levels. From the results of the successes of virtual teaching experience, it can be deduced that teachers found the experience interesting and used multiple virtual platforms to maximize the learning experience for their students. Teachers also recognized the "need for connection" for their students during the pandemic and tried their best to utilize the virtual teaching opportunity to maintain the connection between students and with students. UNICEF (2020) asserted that the COVID-19 pandemic, and ensuing protective measures against the risk of infection, can have significant impact on people's emotional wellbeing - for example, school closures and distance from peers can lead to increasing anger, sadness, fear and anxiety. Teachers took implementation of virtual education as an opportunity to play a variety of roles and make efforts beyond the requirements of the curriculum to ensure effective learning in the virtual setting. Teachers were motivated by the responsibility and care they felt towards their students and it was evident when teachers mentioned putting in extra efforts to engage with their students. Some of the examples of extra efforts by the teachers include arranging one-on-one meetings with each student, using social media to connect with students and parents, experimenting with various digital platforms to make the classroom environment more interactive.

The results depict that teachers made a significant effort to adapt face-to-face teaching to an online setting and were generally successful in making the transition. This transition involved adding additional learning strategies and using multiple platforms to fit their teaching and students' needs. Previous studies (Durlak \& DuPre, 2008; Miller-Day et al., 2013) have supported that adaptation is normal and it usually aids implementation success. As an outcome of this adaptation, teachers were able to learn through their own experience of converting face-to-face teaching practice into virtual teaching practice.

While teachers highlighted successes associated with digital teaching practice, these successes did not come without challenges like lack of student engagement, lack of parents' engagement, need for training need, insufficient access to digital equipment, and systematic challenges. Using Blundell et al.'s (2015) framework of intrinsic (internal) and extrinsic (external) influences on digital technologies in teaching practice, we deem all these highlighted challenges to be extrinsic in nature. Intrinsic challenges are associated with teachers' own attitudes and beliefs; innovation routine; knowledge and skills; vision and design thinking (Blundell et al., 2015), which was not a fundamental issue in digital teaching practice during the COVID-19 pandemic. A study conducted by Ertmer et al. (2001) concluded that the disparity between the practices and constructivist beliefs of the teachers, while implementing digital education, is due to those external barriers. Our study revealed that external barriers like hardware and internet access, access to software and tools, training \& support (administrative, technological, professional, parental and peer) affected teaching practice when teachers shifted from face-to-face to virtual teaching practice. Ertmer et al. (2012) also reported similar challenges as external barriers to digital teaching practice.

Data analysis highlighted the challenges teachers faced during virtual teaching practice due to inequality in access to digital equipment and parental support. Recognizing the need for 'social justice', i.e., all children deserve equal chances to participate; and that 'parents' are not homogeneous and face widely differing factors influencing their capacity for support (Maringe et al., 2015 ) is critical in a situational response. Education leaders being ignorant of these realities, while dispensing education to a vastly diverse cohort of pupils, is an abdication of responsibility (Lumby, 2019).

Given that challenges faced by the teachers were external in nature while implementing digital education, most of the suggestions associated with improving digital teaching practice, were linked to dealing with external barriers to digital teaching practice, e.g., student engagement strategies, training for teachers/students/parents, access to digital equipment, flexible school 
policies and collaboration among teachers. To ensure the effectiveness of digital learning in the future, UNESCO (2020) also proposed preparedness in the context of technological readiness (capacities and equipment), content readiness (teaching and learning materials), pedagogical and home-based learning readiness (teachers' and family readiness) and monitoring and evaluation readiness.

Digital adaptation associated with teaching practice during the unprecedented crisis posed by the COVID-19 pandemic, captured from teachers' perspectives, have highlighted that the respective education systems were not prepared for this transformation. Conducted with an aim to explore what happened with kindergarten and elementary school education during the Corona virus-instigated school closures, our study reveals that there was a successful effort by teachers implement virtual teaching practice. While teaching in a virtual setting, teachers faced multiple challenges and most of these challenges were extrinsic in nature. The current study also sheds light on the insightful suggestions for improvement, from teachers' perspectives, that can be used to inform virtual learning and bring about an improvement in the digital teaching practice.

\section{LIMITATION}

The current study undertaken during the peak COVID-19 pandemic period when schools were closed. Conversely, it has two key limitations, which are as follows:

1. Although we took specific measures to remove the seeding bias while collecting the data via social media, it is uncertain that it has been completely eliminated.

2. The purpose of the current study is to explore what happened on the ground, during the COVID-19 induced school closures, in the context of virtual teaching practice. Consequently, internet survey was used to collect qualitative data from the teachers and therefore we were not able to interview teachers and capture their emotions.

Author contributions: All authors have sufficiently contributed to the study, and agreed with the results and conclusions.

Funding: No funding source is reported for this study.

Declaration of interest: No conflict of interest is declared by authors.

\section{REFERENCES}

Anastasiades, P. S., Filippousis, G., Karvunis, L., Siakas, S., Tomazinakis, A., Giza, P., \& Mastoraki, H. (2010). Interactive Videoconferencing for collaborative learning at a distance in the school of 21st century: A case study in elementary schools in Greece. Computers \& Education, 54(2), 321-339. https://doi.org/10.1016/j.compedu.2009.08.016

Ash, K., \& Davis, M. R. (2009). E-Learning's Potential Scrutinized in Flu Crisis. Education Week, 28(31), 1-12. https://www.edweek.org/issue/2009/05/13

Baker, C., Wuest, J., \& Stern, P. N. (1992). Method slurring: The grounded theory/phenomenology example. Journal of Advanced Nursing, 17(11), 1355-1360. https://doi.org/10.1111/j.1365-2648.1992.tb01859.x

Basilaia, G., \& Kvavadze, D. (2020). Transition to online education in schools during a SARS-CoV-2 coronavirus (COVID-19) pandemic in Georgia. Pedagogical Research, 5(4), 1-9. https://doi.org/10.29333/pr/7937

Blundell, C., Lee, K. T., \& Nykvist, S. (2015). Conceptualising the challenge of integrating digital technologies in pedagogy. Educators on the edge: Big ideas for change and innovation, 44-51. https://eprints.qut.edu.au/90567/

Boston, B. o. b. (2002). Mission impossible? Defining roles, developing courses and overcoming myths in distance education. In D. Willis, J. Price, \& N. Davis (Eds.), Proceedings of SITE 2002--Society for Information Technology \& Teacher Education International Conference (pp. 130-131). Association for the Advancement of Computing in Education (AACE). https://www.learntechlib.org/primary/p/6698/

Brickman Bhutta, C. (2012). Not by the book: Facebook as a sampling frame. Sociological methods \& research, 41(1), 57-88. https://doi.org/10.1177/0049124112440795

Cavanaugh, C., Gillan, K. J., Kromrey, J., Hess, M., \& Blomeyer, R. (2004). The effects of distance education on K-12 student outcomes: A meta-analysis. Learning Point Associates/North Central Regional Educational Laboratory (NCREL). https://eric.ed.gov/?id=ED489533

Clark, T. (2001). Virtual schools: Trends and issues - A study of virtual schools in the United States. Western Regional Educational Laboratories. https://files.eric.ed.gov/fulltext/ED462923.pdf

Cornwell, B., \& Hoagland, E. (2015). Survey methods for social network research. In T. P. Johnson (Ed), Health survey methods (pp. 275-313). https://doi.org/10.1002/9781118594629.ch11

Cutcliffe, J. R. (2003). Reconsidering reflexivity: Introducing the case for intellectual entrepreneurship. Qualitative Health Research, 13(1), 136-148. https://doi.org/10.1177/1049732302239416

Daniel, S. J. (2020). Education and the COVID-19 pandemic. Prospects, 1-6. https://doi.org/10.1007/s11125-020-09464-3

Durlak, J. A., \& DuPre, E. P. (2008). Implementation matters: A review of research on the influence of implementation on program outcomes and the factors affecting implementation. American Journal of Community Psychology, 41(3-4), 327. https://doi.org/10.1007/s10464-008-9165-0 
Ertmer, P. A., Gopalakrishnan, S., \& Ross, E. M. (2001). Technology-using teachers: Comparing perceptions of exemplary technology use to best practice. Journal of Research on Computing in Education, 33(5), 1-26.

Ertmer, P. A., Ottenbreit-Leftwich, A. T., Sadik, O., Sendurur, E., \& Sendurur, P. (2012). Teacher beliefs and technology integration practices: A critical relationship. Computers \& Education, 59(2), 423-435. https://doi.org/10.1016/j.compedu.2012.02.001

Faugier, J., \& Sargeant, M. (1997). Sampling hard to reach populations. Journal of Advanced Nursing, 26(4), 790-797. https://doi.org/10.1046/j.1365-2648.1997.00371.x

Ferdig, R. E. (2006). Assessing technologies for teaching and learning: understanding the importance of technological pedagogical content knowledge. British Journal of Educational Technology, 37(5), 749-760. https://doi.org/10.1111/j.14678535.2006.00559.x

Gauthier, C., Dembélé, M., Bossonnette, S., \& Richard, M. (2004). Quality of teaching and quality of education: A review of research findings. UNESCO. http://citeseerx.ist.psu.edu/viewdoc/download?doi=10.1.1.498.6274\&rep=rep1\&type=pdf

Giannini, S., Jenkins, R., \& Saavedra, J. (2020). Reopening schools: When, where and how? UNESCO Blogs. https://en.unesco.org/news/reopening-schools-when-where-and-how

Groenewald, T. (2004). A phenomenological research design illustrated. International Journal of Qualitative Methods, 3(1), $42-55$. https://doi.org/10.1177/160940690400300104

Hawkins, A., Barbour, M. K., \& Graham, C. R. (2012). "Everybody is their own island": Teacher disconnection in a virtual school. International Review of Research in Open and Distributed Learning, 13(2), 123-144. https://doi.org/10.19173/irrodl.v13i2.967

Jansen, H. (2010). The logic of qualitative survey research and its position in the field of social research methods. In Forum Qualitative Sozialforschung/Forum: Qualitative Social Research, 11(2), 11. https://doi.org/10.17169/fqs-11.2.1450

Keegan, D. (1996). Foundations of distance education (3rd Ed.). Routledge.

Kurtz, G., Beaudoin, M., \& Sagee, R. (2004). From campus to web: The changing roles of faculty from classroom to online teaching. The Journal of Educators Online, 1(1), http://citeseerx.ist.psu.edu/viewdoc/download?doi=10.1.1.412.1238\&rep=rep1\&type=pdf

Lazarus, B. D. (2003). Teaching courses online: How much time does it take. Journal of Asynchronous Learning Networks, 7(3), $47-$ 54. https://pdfs.semanticscholar.org/ea36/1a2a745b068373c4ff2014dcc9480c490a44.pdf

Lee, J. L., \& Hirumi, A. (2004, October). Analysis of essential skills and knowledge for teaching online [Conference Paper]. Association for Educational Communications \& Technology, Chicago, IL, United States. https://eric.ed.gov/?id=ED485021

Lowes, S. (2014). A brief look at the methodologies used in researching online teaching and learning. In R. E. Ferdig, \& K. Kennedy (Eds.), Handbook of research on $\mathrm{K}-12$ online and blended learning (pp. 83-104). ETC Press. https://dl.acm.org/doi/pdf/10.5555/2811036.2811041

Lumby, J. (2010). Leadership for diversity and inclusion. In T. Bush., L. Bell, \& D. Middlewood (Eds.), The principles of educational leadership \& management (2nd Edn., pp. 145-157). Sage.

Maringe, F., Masinire, A., \& Nkambule, T. (2015). Distinctive features of schools in multiple deprived communities in South Africa: Implications for policy and leadership. Educational Management Administration \& Leadership, 43(3), $363-385$. https://doi.org/10.1177/1741143215570303

Marshall, C., \& Rossman, G. B. (2014). Designing qualitative research. Sage publications.

Miller-Day, M., Pettigrew, J., Hecht, M. L., Shin, Y., Graham, J., \& Krieger, J. (2013). How prevention curricula are taught under realworld conditions: Types of and reasons for teacher curriculum adaptations. Health Education, 113(4), 324-344. https://doi.org/10.1108/09654281311329259

Mirabeau, L., Mignerat, M., \& Grangé, C. (2013). The utility of using social media networks for data collection in survey research [Conference Paper]. Thirty Fourth International Conference on Information Systems, Milan, Italy. https://aisel.aisnet.org/cgi/viewcontent.cgi?article=1313\&context=icis2013

Morrow, R., Rodriguez, A., \& King, N. (2015). Colaizzi's descriptive phenomenological method. The Psychologist, 28(8), 643-644. http://eprints.hud.ac.uk/id/eprint/26984/1/Morrow_et_al.pdf

Moustakas, C. (1994). Phenomenological research methods. Sage publications.

Muirhead, W. D. (2000). Online education in schools. International Journal of Educational Management, 14(7), 315-324. https://doi.org/10.1108/09513540010378969

Murphy, E., \& Manzanares, M. A. R. (2008). Contradictions between the virtual and physical high school classroom: A thirdgeneration Activity Theory perspective. British Journal of Educational Technology, 39(6), $1061-1072$. https://doi.org/10.1111/j.1467-8535.2007.00776.x

Murphy, E., \& Rodriguez-Manzanares, M. A. (2009). Sage without a stage: Expanding the object of teaching in a web-based, highschool classroom. International Review of Research in Open and Distributed Learning, 10(3), 1-19. https://doi.org/10.19173/irrodl.v10i3.579

O'Neil, T. (2009). How Distance Education Has Changed Teaching and the Role of the Instructor. Information Systems Education Journal, 7(48), 1-11. http://isedj.org/7/48/

Olson, T., \& Wisher, R. A. (2002). The effectiveness of web-based instruction: An initial inquiry. The International Review of Research in Open and Distributed Learning, 3(2), 1-17. https://doi.org/10.19173/irrodl.v3i2.103 
Palinkas, L. A., Horwitz, S. M., Green, C. A., Wisdom, J. P., Duan, N., \& Hoagwood, K. (2015). Purposeful sampling for qualitative data collection and analysis in mixed method implementation research. Administration and Policy in Mental Health and Mental Health Services Research, 42(5), 533-544. https://doi.org/10.1007/s10488-013-0528-y

Patton, M. Q. (1990). Qualitative evaluation and research methods. Sage publications.

Penrod, J., Preston, D. B., Cain, R. E., \& Starks, M. T. (2003). A discussion of chain referral as a method of sampling hard-to-reach populations. Journal of Transcultural nursing, 14(2), 100-107. https://doi.org/10.1177/1043659602250614

Rogers, F. H., \& Sabarwal, S. (2020). The COVID-19 pandemic: Shocks to education and policy responses (No. 148198, pp. 1-56). The World Bank. http://documents1.worldbank.org/curated/en/365801588601466966/pdf/The-COVID-19-Pandemic-Shocks-toEducation-and-Policy-Responses.pdf

Russell, G. (2004). Virtual schools: A critical view. In C. Cavanaugh (Ed.), Development and management of virtual schools: Issues and trends (pp. 1-26). IGI Global. https://doi.org/10.4018/978-1-59140-154-4.ch001

Sandelowski, M. (1996). One is the liveliest number: The case orientation of qualitative research. Research in Nursing \& Health, 19(6), 525-529. https://doi.org/10.1002/(SICI)1098-240X(199612)19:6<525::AID-NUR8>3.0.CO;2-Q

Savery, J. R. (2005). BE VOCAL: Characteristics of successful online instructors. Journal of Interactive Online Learning, 4(2), $141-152$.

Silverman, D. (2005). Doing qualitative research: A practical handbook. Sage publications.

Tallent-Runnels, M. K., Thomas, J. A., Lan, W. Y., Cooper, S., Ahern, T. C., Shaw, S. M., \& Liu, X. (2006). Teaching courses online: A review of the research. Review of Educational Research, 76(1), 93-135. https://doi.org/10.3102/00346543076001093

Thamarana, S. (2016). Role of e-learning and virtual learning environment in English language learning role of e-learning and virtual learning environment in English [Coneference Paper]. Teaching English language and literature: Innovative methods and practices, ELTAI Tirupati, India.

Tinsley, H. E., \& Weiss, D. J. (1975). Interrater reliability and agreement of subjective judgments. Journal of Counseling Psychology, 22(4), 358. https://doi.org/10.1016/B978-012691360-6/50005-7

Tufford, L., \& Newman, P. (2012). Bracketing in qualitative research. Qualitative Social Work, 11(1), 80-96. https://doi.org/10.1177/1473325010368316

UNESCO. (2020). Education from disruption to recovery. UNESCO Blogs. https://en.unesco.org/covid19/educationresponse

UNESCO. (2020, April). Distance learning strategies in response to COVID-19 school closures (Programme and Meeting Document ED/2020/IN2.1/REV). https://unesdoc.unesco.org/ark:/48223/pf0000373305/PDF/373305eng.pdf.multi

UNICEF. (2020). Emotional wellbeing in the time of COVID-19. UNICEF Blog. https://www.unicef.org/northmacedonia/emotionalwellbeing-time-covid-19

Viner, R. M., Russell, S. J., Croker, H., Packer, J., Ward, J., Stansfield, C., Mytton, O., Bonell, C., \& Booy, R. (2020). School closure and management practices during coronavirus outbreaks including COVID-19: a rapid systematic review. The Lancet Child \& Adolescent Health, 4(5), 397-404. https://doi.org/10.1016/S2352-4642(20)30095-X

Watson, J. F., Winograd, K., \& Kalmon, S. (2004). Keeping pace with K-12 online learning: A snapshot of state-level policy and practice. Learning Point Associates/North Central Regional Educational Laboratory (NCREL). https://files.eric.ed.gov/fulltext/ED518634.pdf

Welman, J., \& Kruger, S. (1999). Research methodology for the business and administrative sciences. International Thompson. 